- WATERWAYS EXPERIMENT STATION TRACT REPORT No. 2-136

REPORT NO. $2-136$

\title{
FEASIBILITY STUDY FOR A SURGE-ACTION MODEL OF MONTEREY HARBOR, CALIFORNIA
}

by

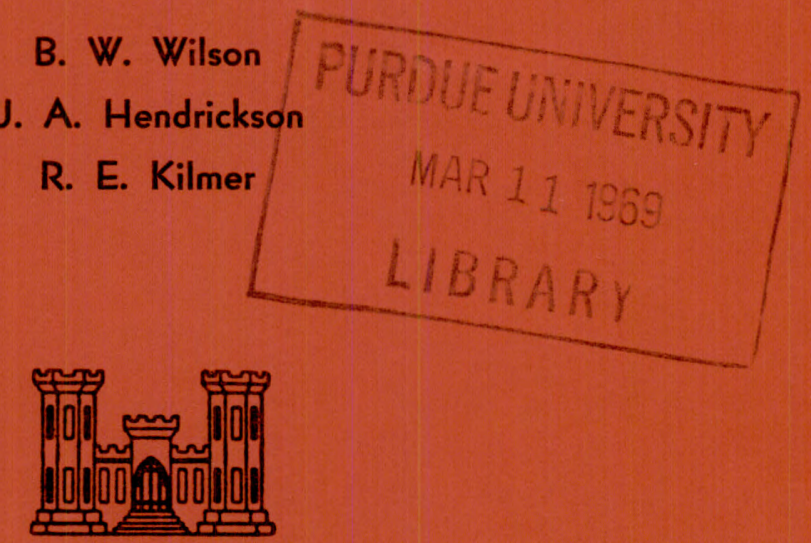

October 1965

Sponsored by

U. S. Army Engineer District

San Francisco

CIVIL ENGIMEERIHG TECHURAL REPORT

I IBRARY

Prepared for

U. S. Army Engineer Waterways Experiment Station CORPS OF ENGINEERS

Vicksburg, Mississippi

\section{Under}

Contract No. DA-22-079-civeng-65-10

by

Science Engineering Associates

San Marino, California

DISTRIBUTION OF THIS DOCUMENT IS UNLIMITED

Mr:.31 